\title{
O EMPREGO AGRÁRIO E O INVESTIMENTO SUBSIDIADO: EVIDÊNCIA INICIAL DE SEIS CONCELHOS DURIENSES NO PERÍODO DE 1986-1997*
}

\author{
Ibraima Guei Ganó** \\ Chris Gerry ${ }^{* * *}$ \\ José Vaz Caldas****
}

\begin{abstract}
Ao longo das últimas décadas tem-se assistido a uma progressiva diminuição da população do Douro, explicada quer por movimentos migratórios quer, mais recentemente, por crescimentos naturais negativos. Esta evolução demográfica tem vindo a afectar negativamente o sector agrário desta região, a sua actividade económica dominante e, consequentemente, o seu desenvolvimento socioeconómico.

Após a adesão de Portugal à CEE, e no âmbito da PAC, foram concedidos ao sector agrário subsídios a investimentos para a reconversão produtiva e tecnológica, bem como incentivos à fixação de jovens, nomeadamente com o objectivo de modernizar e melhorar a competitividade do sector agrário e viabilizar o desenvolvimento das zonas rurais. Uma das políticas consideradas a priori capaz de contribuir para a estabilização do emprego existente e para a criação de postos de trabalho foi a subsidiação de actividades produtivas
\end{abstract}

\footnotetext{
** Licenciado em Gestão e Mestre em Agricultura, Ambiente e Mercados pela Universidade de Trás-os-Montes e Alto Douro (UTAD); actualmente a doutorar-se em Administração e Direcção de Empresas na Universidade de Barcelona.

*** Professor Associado com Agregação no Departamento de Economia e Sociologia (DES)

**** Professor Auxiliar no DES da UTAD e docente do Instituto Universitário do Desenvolvimento e Promoção Social - Pólo de Viseu da Universidade Católica Portuguesa.
} da UTAD. 
agro-rurais. Assim, este trabalho tem como objectivo mostrar alguns dos principais efeitos-emprego do investimento agrícola subsidiado na região do Douro, no âmbito dos Regulamentos comunitários $n^{\circ} 797 / 85$ e 2328/91, e apurar os custos por posto de trabalho a criar. Para esse efeito foram analisados 359 planos de melhoria aprovados pelo Instituto de Financiamento e Apoio ao Desenvolvimento da Agricultura e das Pescas (IFADAP) no periodo de 1986-1997.

$A$ análise dos resultados obtidos permite-nos concluir que: os pequenos projectos são, de um modo geral, os que propiciam a criação de mais emprego; o investimento subsidiado desempenha um papel importante, tanto na viabilização das pequenas explorações como na dinamização socioeconómica local, pois contribui sobretudo nas iniciativas geridas por Jovens Agricultores - para a consolidação do emprego do próprio promotor e para a eventual criação de emprego para os membros da sua família elou para membros da sua própria comunidade.

Palavras-chave: Efeito-emprego; investimento subsidiado; planos de melhoria.

\section{INTRODUÇÃO}

Segundo os resultados preliminares dos Censos de 2001, residiam na região do Douro 221568 habitantes, o que representa uma perda de 7\% da sua população, relativamente ao Recenseamento de 1991. Contudo, a parte mais significativa desta perda verificou-se na década de 80 , a uma taxa média anual de contracção de aproximadamente 1\% (Rebelo et al., 2001). Segundo estes autores, até finais da década de 80 , a diminuição dos efectivos populacionais no Douro era explicada por movimentos migratórios, uma autêntica "fuga" para o litoral ou para o estrangeiro; no entanto, o envelhecimento provocado por estas migrações deu origem a uma situação em que a mortalidade supera a natalidade na maior parte dos concelhos durienses, ou seja, tem vindo a assistir-se recentemente a crescimentos naturais negativos. São excepções nesta evolução Vila Real, Lamego, Peso da Régua e Mesão Frio, fruto de um fenómeno particularmente marcante da evolução demográfica na década de 90 , a concentração urbana. 

concelhos durienses no período de 1986-1997

Perante os dados dos Censos de 2001, a principal conclusão que se pode retirar sobre a recente evolução da população duriense é a de um "padrão de urbanização crescente, caracterizado por na maior parte do território ocorrerem processos de perda populacional mas, em simultâneo, os principais aglomerados populacionais dos concelhos terem uma evolução contrária, vendo crescer a sua população" (Rebelo et al., 2001). E, quando complementamos a descrição desta recente evolução demográfica com a análise da estrutura etária, só podemos concluir que a tendência de regressão demográfica vai continuar. Mesmo que a taxa de fecundidade venha a aumentar, a actual ausência de população jovem não permite perspectivar uma evolução positiva da taxa de natalidade, pelo que só uma significativa criação de emprego, que incentive a fixação de jovens, poderá abrir uma oportunidade de inversão desta tendência, como aconteceu, nomeadamente, na área urbana de Vila Real (Rebelo et al., 2001).

No entanto, os poucos empregadores do Interior queixam-se da falta de mão-de-obra qualificada, enquanto que os jovens - sobretudo mulheres - que optam por ficar no meio rural, enfrentam grandes dificuldades em encontrar emprego por eles considerados satisfatório, em termos quer de remuneração, quer de estabilidade. Como Gerry, António e Portela (2001: 2-3) constatam:

Enquanto que o emprego no Douro cresceu em $9 \%$ no período de 1995-1997, o desemprego [em muitos concelhos ...] aumentou [...] exactamente na mesma altura em que a tendência para Portugal ia no sentido decrescente. Esta situação explica-se por duas razões essenciais. Por um lado, a economia local tem-se mostrado incapaz de absorver o número relativamente modesto de jovens que entram anualmente no mercado de trabalho. Por outro lado, tem-se assistido [...] a melhorias na obtenção de dados estatísticos bem como na classificação de pessoas que eram consideradas inactivas e que passaram a inscrever-se como desempregadas

$\dot{E}$ amplamente reconhecido que o desemprego é particularmente problemático na população activa jovem, sendo as mulheres as mais afectadas. Este fenómeno [...] é bastante mais expressivo na região do Douro comparativamente às restantes regiões do país.

Em termos de afectação da população activa, na região do Douro a actividade económica dominante continua a ser a agricultura. Daí que a forte pressão para a emigração e a transferência da população residente para outras actividades (principalmente no sector terciário, fruto do 
padrão de urbanização crescente nas últimas décadas) tenha afectado principalmente o sector agrário. Espelho desta situação é a redução de $16 \%$ no número de explorações agrárias e de $9,5 \%$ na sua superfície agrícola útil (Caldas e Rebelo, 2001).

Presentemente, o sector agrário contribui ainda com cerca de $40 \%$ para o Produto Interno Bruto da Região do Douro (FRAH, 2000), compreendendo 139097 ha de superfície agrícola útil (SAU) e perto de 32000 explorações, com uma dimensão média de 4,35 ha (INE, 2000). A importância do sector primário nos concelhos durienses de Tabuaço, Alijó, Sabrosa e Santa Marta de Penaguião é claramente dominante ${ }^{1}$, ainda que em determinados concelhos, como os de Vila Nova de Foz Côa e Torre de Moncorvo o peso relativo dos sectores primário e terciário seja semelhante $^{2}$ e, noutros, como nos de Vila Real, Régua e Lamego, o sector terciário seja maioritário ${ }^{3}$. Mas, dada a reconhecida tendência das estatísticas para ignorar uma parte dos activos agrícolas (classificados, nomeadamente, como domésticas e pensionistas), o peso real do sector agrário é com certeza superior ao revelado pelas mesmas.

A partir de 1986, com a integração na Comunidade Europeia, Portugal passou a beneficiar de recursos provenientes dos seus Fundos Estruturais. Assim, o sector agrário português passou a dispor de uma política comunitária de estruturas agrícolas financiada pelo Fundo Europeu de Orientação e Garantia Agrícola (FEOGA).

Com a progressiva introdução da Política Agrícola Comum (PAC) em Portugal, procurou-se modernizar e melhorar a competitividade do sector agrário, contribuindo para uma utilização mais eficiente dos recursos naturais e produtivos, para que a população rural possa usufruir de boas condições de vida e de trabalho e para viabilizar o desenvolvimento sócio-económico das zonas rurais. Foram por isso concedidos, nomeadamente, subsídios para investimentos em formação, reconversão produtiva e tecnológica, bem como incentivos à fixação de jovens, no âmbito dos Regulamentos Comunitários 797/85 e 2328/81.

É de lamentar a falta de estudos, quer específicos, quer comparativos, sobre a performance destes investimentos subsidiados. Todavia, esta carência é perceptível devido à existência de problemas práticos e metodológicos na sua realização, sobretudo no que respeita:

- ao tempo necessário para que os efeitos dos vários tipos de investimentos se manifestem,

- à dificuldade de construir uma amostra representativa das principais e emergentes fileiras produtivas, das assimetrias 
estruturais, dos graus variáveis de participação e de empenho dos diferentes concelhos, e

- ao problema de escolher uma metodologia de avaliação que reúna a precisão e comparabilidade das análises, baseadas em critérios técnico-financeiros, com a sensibilidade qualitativa das análises assentes nos conceitos de sistemas de produção e tecido e dinâmicas empresariais/institucionais.

Porém, visto que um dos objectivos das políticas agrárias e rurais embora, até recentemente, não prioritário - tem sido a fixação da população jovem através de melhorias nas oportunidades locais de emprego, é pertinente o nosso esforço no sentido de avaliar o impacto da aplicação de fundos públicos na criação de emprego rural. Como acima referimos, uma das políticas considerada, a priori, capaz de contribuir para a estabilização do emprego existente e para a criação de novos postos de trabalho tem sido a subsidiação de investimentos em actividades produtivas agrícolas ou rurais. Assim, os principais objectivos do presente estudo são:

1) mostrar alguns dos principais efeitos-emprego do investimento agrícola subsidiado na região do Douro, pois o balanço destes é um elemento importante na avaliação dos instrumentos aplicados na promoção do desenvolvimento rural;

2) relacionar os montantes investidos e os subsídios pagos por fundos públicos com o número total de postos de trabalho a criar, de forma a obter o custo por posto de trabalho em termos de subsídios pagos e capital próprio investido.

A primeira etapa desta investigação envolveu a análise de 359 formulários de projectos de investimento aprovados pelo Instituto de Financiamento e Apoio ao Desenvolvimento da Agricultura e das Pescas (IFADAP), em 6 concelhos durienses, nomeadamente os de Alijó, Moimenta da Beira, Sabrosa, Tabuaço, Torre de Moncorvo e Vila Nova de Foz Côa. A estrutura deste trabalho é a seguinte: na secção 2 debruçamo-nos sobre os dados recolhidos; na secção 3 analisam-se os resultados em termos dos efeitos-emprego, e respectivos custos, do investimento subsidiado. Na secção 4 apresentam-se as conclusões e levantam-se algumas questões de ordem estratégica ligadas às políticas de emprego e desenvolvimento nas zonas rurais do Interior. 


\section{DADOS}

Nas Secções 2.1., 2.2., 2.3. e 2.4., efectuamos, respectivamente, algumas considerações acerca da recolha de dados, representatividade da amostra, metodologia adoptada e das limitações da informação utilizada.

\subsection{A recolha de dados}

No estudo realizado os dados foram recolhidos da seguinte forma:

- Análise de 359 projectos de investimento aprovados pelo IFADAP, entidade que assegura a promoção, selecção, avaliação e acompanhamento inicial de planos de melhoria das explorações agrárias subsidiados no âmbito dos Regulamentos Comunitários No 797/85 e 2328/91, no período de 1986-1997, nos seis concelhos da região do Douro já referidos. Os subsídios, com base nestes regulamentos, foram concedidos na forma de ajudas financeiras a fundo perdido e, tipicamente, correspondem a cerca de $55 \%$ do montante do investimento pretendido.

- O total dos projectos analisados representa uma amostra de cerca de $25 \%$ dos projectos aprovados para cada um dos seis concelhos, no período acima referido. Assim, foram consultados 40 projectos de Alijó, 60 de Tabuaço, 60 de Sabrosa, 70 de Moimenta da Beira, 72 de Torre de Moncorvo e 77 de Vila Nova de Foz Côa. Recolheu-se informação sobre a dimensão, o tipo de investimento realizado e as intenções do promotor no que respeita à criação de postos de trabalho, bem como a relativa a indicadores técnicos e económicos.

- Os investimentos realizados de 1986 a 1997 incidiram, fundamentalmente, na realização de melhoramentos fundiários, construções e plantações, e na aquisição de máquinas e equipamento.

\subsection{Questões acerca da representatividade da amostra}

A nossa análise incidiu sobre 6 concelhos, de entre os 19 da região do Douro, que nos pareceram relativamente homogéneos em termos das suas principais fileiras produtivas. Foi seleccionado aleatoriamente um quarto 

concelhos durienses no período de 1986-1997

dos planos de melhoria aprovados em cada um dos concelhos estudados, o que forneceu uma amostra razoável, em termos tanto absolutos (359 casos) como relativos ( $25 \%$ do universo).

O nosso conhecimento do sector agrícola duriense, acumulado no estudo de outros projectos de investigação, permitiu-nos também concluir que estes 6 concelhos são, de modo geral, representativos nas perspectivas:

1) da estrutura produtiva da região, embora, evidentemente, com certas variações na importância relativa de um leque de culturas-chave e de determinados sistemas e escalas de produção;

2) das dinâmicas empresarial e institucional da região, embora, também, com certa variabilidade, em termos tanto do avanço de determinadas formas empresariais e associativas, como de um ambiente propício ao desenvolvimento local atribuível ao empenho do poder local e/ou das instituições locais ${ }^{4}$; e

3) da situação geral, ao nível da região duriense, no que respeita à aplicação de capitais próprios e de subsídios com intuito de viabilizar e modernizar as explorações agrícolas.

Atendendo a que o objectivo principal deste estudo é analisar o comportamento do investimento realizado por pequenos e médios produtores agrários, no contexto da sua fileira e concelho, e avaliar o efeito-emprego das suas decisões, após uma apreciação do histograma das despesas previstas, excluímos propositadamente um número muito limitado de planos, por serem investimentos contemplados, por exemplo, por empresas vitivinícolas de grandes dimensões e que considerámos atipicamente avultados.

\subsection{A metodologia adoptada na avaliação do efeito-emprego}

A avaliação do impacto agregado das ajudas concedidas aos investidores (investimento subsidiado), em termos da criação de emprego, será feita pela quantificação do número de postos de trabalho que os promotores pretendem criar directamente em consequência da execução física dos investimentos, medidos em Unidades Homem Trabalho $(\mathrm{UHT})^{5}$. Assim, a nossa análise incide ex ante sobre o emprego a criar (ou seja, as intenções do promotor) e não ex post sobre os postos de trabalho efectivamente criados. 
Nesta avaliação distingue-se a criação de postos de trabalho, para membros da família, da de assalariados não familiares. Esta distinção justifica-se pela diferença que os efeitos do investimento subsidiado têm na mão-de-obra familiar não assalariada e na não familiar remunerada. Por um lado, no emprego familiar, procura-se, principalmente, mesmo no caso de uma estratégia familiar pluriactiva, uma viabilização "limitada" da actividade da exploração, pela extensão de oportunidades de emprego, quer para o próprio investidor, quer para a sua família. Por outro lado, o efeito da contratação de mão-de-obra não familiar remunerada, para além de permitir a consolidação económica da exploração, contribui também para a viabilização socioeconómico alargada da economia local através da absorção de mão-de-obra desempregada e/ou subempregada, muita dela jovem, assim como para a reversão da tendência para (e)migração verificada nas últimas décadas, através dos efeitos multiplicadores desencadeados.

No cálculo das UHTs familiares e das UHTs assalariadas não familiares incluímos todo o emprego permanente a ser criado, independentemente de ser a tempo parcial ou a tempo inteiro.

Neste trabalho, estamos ainda interessados em calcular tanto o custo total da criação de emprego, como o das suas componentes, ou seja, o que é suportado por despesas públicas e o que é assumido, directa ou indirectamente $^{6}$, pelos próprios promotores. $\mathrm{O}$ custo da criação de um posto de trabalho suportado pela Comunidade Europeia e pelo Estado Português é calculado pelo rácio subsídios/ acréscimo de UHTs. O custo da criação de uma UHT por capital próprio, isto é, suportado financeiramente pelo promotor agrícola, é obtido pelo rácio capitais próprios/ acréscimo de UHTs. Consequentemente, o custo total da criação de um posto de trabalho é medido pelo rácio montante de investimentos/acréscimo de UHTs, ou seja subsídios + capitais próprios/ acréscimo de UHTs.

\subsection{As limitações dos dados}

A informação recolhida nos planos de melhoria sofre de certas limitações que devem ser levadas em conta na interpretação dos resultados, das quais as mais importantes são:

1) A fiabilidade dos dados recolhidos. Inerentes a qualquer processo de inquirição directa ou indirecta, podem existir 

concelhos durienses no periodo de 1986-1997

imprecisões nas informações fornecidas pelos inquiridos/ promotores do investimento, quer propositadamente, de forma a poderem maximizar o subsídio a receber (independentemente ou influenciados por assessores formais ou informais), quer indevidamente, por ignorância, lapso, etc.;

2) A adequação dos dados disponíveis. É também de referir a inadequação habitual entre os objectivos de selecção, avaliação e acompanhamento implícitos no processo de inquirição realizado por um organismo financiador e os objectivos da análise socioeconómica (Gerry, Vaz Caldas e Koehnen, 1999: 72);

3) A influência de terceiros na formulação dos planos de melhoria. Pela análise cuidadosa dos planos de melhoria, foi-nos possível perceber que alguns deles não foram elaborados pelo próprio promotor, antes por assessores vulgarmente conhecidos como projectistas, reproduzindo assim "informação-tipo" que não reflecte de forma precisa os planos futuros do promotor.

Não obstante estas reservas quanto à qualidade da informação disponível, esta constitui um bom ponto de partida para a avaliação das intenções dos promotores, no que respeita à criação de postos de emprego na base de investimentos subsidiados aprovados pelo IFADAP.

\section{RESULTADOS}

Na secção 3.1., procede-se à análise do efeito-emprego e respectivo custo, tendo em conta, primeiro a dimensão do investimento realizado e, a seguir, na secção 3.2. a sua finalidade. $\mathrm{Na}$ secção 3.3., efectuamos uma análise do efeito-emprego previsto e respectivo custo, por concelho, tipo de emprego e idade de promotor, pois esta permite-nos apontar o impacto diferencial da estrutura produtiva e dos tecidos empresarial e institucional que os distintos concelhos durienses apresentam.

\subsection{Análise da criação de emprego e seu custo, por dimensão do investimento}

Na criação do emprego, em consequência do investimento subsidiado na agricultura, é relevante a dimensão dos montantes dos investimentos realizados (Gomes e Rombo, 1999). 
$\mathrm{Na}$ pesquisa da relação entre a dimensão do investimento e as intenções de criação de emprego, procedemos ao agrupamento dos vários projectos na nossa base de dados inicial, em classes de investimento com intervalos de 5000 contos. Os investimentos foram agrupados em quatro classes $^{7}$, a primeira compreendendo os projectos iguais ou inferiores a 5000 contos e, a última, abrangendo os superiores a 15000 contos. Para cada classe foram apurados o montante de investimento total (o somatório do subsídio mais capitais próprios), as UHTs a serem criadas e os respectivos custos.

O Quadro 1 permite-nos comparar, para projectos com diferentes dimensões, as UHTs a criar e os montantes dos investimentos previstos, quer em termos de subsídios concedidos, quer dos capitais próprios (ou seja, autofinanciamento) a serem mobilizados pelos promotores.

\section{Quadro 1 \\ EMPREGO A CRIAR E O CUSTO POR UHT, POR DIMENSÃO DE INVESTIMENTO}

\begin{tabular}{|c|c|c|c|c|c|c|c|}
\hline $\begin{array}{c}\text { Classe de } \\
\text { investimen } \\
\text { to }\end{array}$ & $\begin{array}{c}\text { Investime } \\
\text { nto } \\
\text { (contos) }\end{array}$ & $\begin{array}{l}\text { Subsídio } \\
\text { (contos) }\end{array}$ & $\begin{array}{l}\text { Capitais } \\
\text { Próprios } \\
\text { (contos) }\end{array}$ & $\begin{array}{l}\text { UHT total } \\
\text { (contos) }\end{array}$ & $\begin{array}{c}\text { Invest./UH } \\
\mathbf{T} \\
\text { (contos) }\end{array}$ & $\begin{array}{c}\text { Subsídio/U } \\
\text { HT } \\
\text { (contos) }\end{array}$ & $\begin{array}{l}\text { Capitais } \\
\text { próprios/ } \\
\text { UHT } \\
\text { (contos) }\end{array}$ \\
\hline Até 5000 & 512270 & 281748 & 230521 & 496 & 1032 & 568 & 464 \\
\hline $\begin{array}{l}5000 \mathrm{a} \\
10000\end{array}$ & 484584 & 266521 & 218063 & 229 & 2112 & 1162 & 951 \\
\hline $\begin{array}{l}10000 \mathrm{a} \\
15000\end{array}$ & 351965 & 193581 & 158384 & 73 & 4813 & 2647 & 2166 \\
\hline $\begin{array}{l}15000 \mathrm{e} \\
\text { mais }\end{array}$ & 726334 & 399484 & 326850 & 118 & 6143 & 3379 & 2765 \\
\hline Total & 2075154 & 1141334 & 933819 & 918 & & & \\
\hline
\end{tabular}

Fonte: IFADAP. Valores calculados a partir da informação contida na amostra de planos de melhoria.

Concluímos do Quadro 1 que os pequenos projectos são, de um modo geral, os que geram mais emprego e que o custo das UHTs, a serem criadas, cresce com a dimensão dos projectos. 

concelhos durienses no período de 1986-1997

\subsection{Análise da criação de emprego, por finalidade do investimento}

Devido ao carácter muitas vezes "misto" dos projectos, ou seja, de investimentos que visam responder a vários aspectos da modernização da exploração, é difícil atribuir quantitativamente a criação de um posto de trabalho a determinada finalidade. Além disso, a categorização de finalidades dos investimentos aplicada pelo IFADAP, reflectida nos dados por nós consultados, embora perfeitamente lógica na perspectiva administrativa, nem sempre é conducente aos objectivos analíticos. No entanto, como primeira aproximação, podemos relacionar o emprego a ser criado, através dos investimentos contemplados nos planos de melhoria aprovados, com as finalidades que, em todos os concelhos analisados, se revelaram mais importantes.

\section{Quadro 2 \\ INVESTIMENTOS SUBSIDIADOS, POR FINALIDADE DE INVESTIMENTO}

\begin{tabular}{|c|c|c|c|c|c|c|c|}
\hline Concelhos & Alijó & $\begin{array}{c}\text { Moi- } \\
\text { menta } \\
\text { da Beira }\end{array}$ & Sabrosa & $\begin{array}{c}\text { Torre de } \\
\text { Mon- } \\
\text { corvo }\end{array}$ & Tabuaço & $\begin{array}{c}\text { V. N. } \\
\text { F. Côa }\end{array}$ & Total \\
\hline $\mathrm{N}^{\mathrm{o}}$ de planos de melhoria & 40 & 70 & 60 & 72 & 60 & 77 & 359 \\
\hline Investimento Total (contos) & 419449 & 433448 & 282167 & 359940 & 252192 & 327958 & 2075154 \\
\hline Melhoramentos Fundiários (\%) & 5 & 10 & 4,5 & 8 & 9,5 & 3 & 7 \\
\hline Construções (\%) & 12 & 8,5 & 22 & 11 & 10 & 9 & 11,5 \\
\hline Máquinas (\%) & 51 & 50 & 44 & 45,5 & 36 & 46 & 46 \\
\hline Plantações (\%) & 32,5 & 32 & 30 & 36 & 44,5 & 43 & 36 \\
\hline
\end{tabular}

Fonte: IFADAP. Valores calculados a partir da informação contida na amostra de planos de melhoria.

Da leitura do Quadro 2 somos levados a concluir que, na base das intenções e previsões manifestadas nos planos de melhoria, os tipos de investimento que mostram ser os mais potenciadores de criação de emprego são maioritariamente orientados para duas finalidades, nomeadamente a aquisição de maquinaria e equipamentos e a realização de plantações.

No que respeita à primeira - que, em muitos casos, se aproxima de metade do investimento pretendido -, é importante salientar que é bastante abrangente ${ }^{8}$. Convém ainda estar consciente do facto de que, 
típica e tendencialmente, estes investimentos poderem promover uma acelerada substituição de mão-de-obra, sendo neutros ou contraproducentes em termos do efeito-emprego líquido.

Quanto à plantação ou replantação, sobretudo de vinha, mas também de pomares e olivais, é mais provável que o efeito-emprego líquido seja positivo. Ainda que estas iniciativas permitam por exemplo, a mecanização parcial da cultura e colheita da maçã, também envolvem, eventualmente, a aquisição e plantação de pomares adicionais, novas variedades e sistemas culturais mais exigentes em termos de mão-de-obra qualificada, com consequentes melhoramentos não só da produtividade, mas também da qualidade da fruta, e o acesso a novos mercados mais lucrativos que, no conjunto, têm efeitos-emprego líquidos positivos, quer directos, quer indirectos 9 .

\subsection{Análise da criação de emprego e seu custo, por concelho}

Para além de calcularmos o custo da criação de um posto de trabalho, numa perspectiva mais qualitativa, torna-se relevante saber que tipo de emprego é contemplado nos investimentos a serem realizados. Será que, como nos questionávamos no início deste trabalho, o emprego a criar ocupará fundamentalmente mão-de-obra familiar mais intensamente, reflectindo assim a concretização de uma estratégia de viabilização empresarial essencialmente limitada ao agregado familiar, ou contribuirá mais para a viabilização socioeconómica local, através da contratação de pessoas alheias à exploração e à família? Antes de tentarmos distinguir entre estes dois resultados interligados (ver Secções 3.3.2. e 3.3.3.), apresentaremos na Secção 3.3.1. a nossa avaliação do efeito-emprego total resultante do investimento subsidiado.

\subsubsection{Investimento subsidiado e criação de emprego em termos globais}

No período de 1986 a 1997, registou-se um investimento total de 2075154 contos, subsidiado a fundo perdido em cerca de 55\% por verbas comunitárias e nacionais. Em consequência directa destes investimentos prevê-se que serão criados 918 postos de trabalho ${ }^{10}$. Houve ainda um quantidade indeterminada de UHTs, quase impossível de 

concelhos durienses no periodo de 1986-1997

quantificar, gerada de forma indirecta, ou seja, através dos efeitos multiplicadores "clássicos", parcialmente ou totalmente em consequência destes investimentos, a nível das empresas situadas a montante e jusante das explorações sob análise.

O custo do investimento total necessário para a criação de uma UHT adicional, a nível dos concelhos estudados, é em média de 2261 contos. Este custo total decompõe-se em duas componentes: (1) o subsídio médio nacional e comunitário que, em média, é de 1243 contos; e (2) o custo suportado pelo agricultor que, em média, é de 1017 contos.

\section{Quadro 3 \\ EMPREGO TOTAL A CRIAR E O CUSTO POR UHT, POR PLANO DE MELHORIA E CONCELHO}

\begin{tabular}{|c|c|c|c|c|c|c|c|}
\hline Concelhos & Alijó & $\begin{array}{c}\text { Moi- } \\
\text { menta } \\
\text { da } \\
\text { Beira }\end{array}$ & Sabrosa & $\begin{array}{l}\text { Torre } \\
\text { de } \\
\text { Mon- } \\
\text { corvo }\end{array}$ & $\begin{array}{c}\text { Tabu- } \\
\text { aço }\end{array}$ & $\begin{array}{c}\text { Vila } \\
\text { Nova de } \\
\text { Foz Côa }\end{array}$ & $\begin{array}{c}\text { Todos } \\
\text { conce- } \\
\text { lhos }\end{array}$ \\
\hline Investimento total (contos) & 419449 & 433448 & 282167 & 359940 & 252192 & 327958 & 2075154 \\
\hline $\begin{array}{l}\text { Investimento por plano de } \\
\text { melhoria (contos) }\end{array}$ & 10486 & 6192 & 4703 & 4999 & 4203 & 4259 & 5780 \\
\hline Subsídios (contos) & 230697 & 238396 & 155192 & 197967 & 138705 & 180377 & 1141334 \\
\hline Capitais próprios (contos) & 188752 & 195052 & 126975 & 161973 & 113486 & 147581 & 933819 \\
\hline Total de UHTs a criar & 135 & 139 & 99 & 253 & 89 & 203 & 918 \\
\hline $\mathrm{N}^{0}$ de planos de melhoria & 40 & 70 & 60 & 72 & 60 & 77 & 359 \\
\hline UHTs por plano de melhoria & 3,4 & 2 & 1,7 & 3,5 & 1,5 & 2,6 & 2,6 \\
\hline Investimento/UHTs (contos) & 3107 & 3118 & 2850 & 1423 & 2834 & 1616 & 2261 \\
\hline Subsídio/UHTs (contos) & 1709 & 1715 & 1568 & 782 & 1558 & 889 & 1243 \\
\hline $\begin{array}{l}\text { Capitais próprios/UHTs } \\
\text { (contos) }\end{array}$ & 1398 & 1403 & 1283 & 640 & 1275 & 727 & 1017 \\
\hline
\end{tabular}

Fonte: IFADAP. Valores calculados a partir da informação contida na amostra de planos de melhoria.

Em termos de emprego total a criar, destacam-se Torre de Moncorvo e Vila Nova de Foz Côa, com um total de 253 e 203 postos de trabalho, o que corresponde a $28 \%$ e $22 \%$, respectivamente, de todo o emprego a criar nos concelhos estudados. É também nestes concelhos que o custo dos investimentos subsidiados e, consequentemente, a aplicação de capitais próprios por UHT, é o mais baixo. Uma possível explicação para estes valores deve-se mais às diferenças inter-concelhias no ambiente externo do que às próprias características das empresas envolvidas. Mais 
especificamente, é de salientar o maior apoio institucional dado ao nível destes concelhos, que possibilita que os agricultores disponham de mais e melhor informação técnico-económica no âmbito do investimento a realizar, a par de uma dinâmica empresarial relativamente mais desenvolvida e bem sucedida.

No que respeita ao caso específico de Vila Nova de Foz Côa, para além dos efeitos no tecido empresarial e na densidade institucional, devido à descoberta e exploração do património arqueológico local, existem certas empresas locais, nomeadamente a Adega Cooperativa, cujo dinamismo tem promovido, tanto a montante, como a jusante, efeitos multiplicadores quantitativos e qualitativos bastante positivos. No caso de Torre de Moncorvo, ocorreu um processo semelhante, embora por razões diferentes, nomeadamente o impacto aglutinador de determinadas instituições locais, tais como o Gabinete de Apoio Técnico, a Zona Agrária (da DRATM) e várias organizações associativas ligadas à formação e à divulgação de práticas de Protecção Integrada.

No caso de Alijó verificamos que, embora seja o segundo concelho, tanto em termos do montante de investimento proposto, como do número de UHTs a serem criadas por projecto, é também aquele onde o custo de cada UHT é dos mais elevados. Pensamos ser necessária a realização de investigação adicional - sobretudo inquéritos mais qualitativos com as empresas envolvidas - para a compreensão clara desta constatação.

No que respeita à qualidade do emprego criado, pelo menos no âmbito das medidas de promoção de Jovens Agricultores, a obrigatoriedade de manter as explorações nos moldes projectados, durante cinco anos, traduz-se numa confortável garantia adicional, tanto para os gestores destes iniciativas, como para os eventuais trabalhadores a serem contratados, de que existe alguma durabilidade nos postos de trabalho criados (Gomes e Rombo, 1999).

Não existindo dados disponíveis quanto à remuneração de novos trabalhadores contratados resultante do investimento subsidiado, é de salientar que, apesar das queixas de muitos empresários agrários sobre o elevado custo, baixa produtividade e capacidades limitadas da mão-de-obra rural existente, nem os salários em vigor na agricultura portuguesa $^{11}$, nem as condições de trabalho, são suficientemente atractivos para a geração mais jovem. 

concelhos durienses no período de 1986-1997

\subsubsection{A criação/extensão do emprego familiar}

No que diz respeito especificamente à criação de novos postos de trabalho para membros da família do promotor e/ou à extensão de empregos familiares já existentes, pela leitura dos resultados do Quadro 4 podemos concluir que esta foi mais elevada em Vila Nova de Foz Côa e em Moimenta da Beira. Quanto ao seu custo, foram também estes os concelhos que apresentaram valores mais baixos. Em certa medida, esta realidade está associada às características próprias destes concelhos, nomeadamente a sua estrutura fundiária (ou seja, a preponderância de explorações de relativamente pequenas dimensões), factor que influencia tanto o montante de investimento que pode ser absorvido, como a sua finalidade.

\section{Quadro 4}

\section{EMPREGO FAMILIAR A CRIAR E O CUSTO POR UHT, POR PLANO DE MELHORIA E CONCELHO}

\begin{tabular}{|c|c|c|c|c|c|c|c|}
\hline Concelhos & Alijó & $\begin{array}{c}\text { Moi- } \\
\text { menta } \\
\text { da } \\
\text { Beira }\end{array}$ & Sabrosa & $\begin{array}{c}\text { Torre } \\
\text { de Mon- } \\
\text { corvo }\end{array}$ & $\begin{array}{c}\text { Tabu- } \\
\text { aço }\end{array}$ & $\begin{array}{c}\text { Vila } \\
\text { Nova } \\
\text { de Foz } \\
\text { Côa }\end{array}$ & $\begin{array}{c}\text { Todos } \\
\text { conce- } \\
\text { lhos }\end{array}$ \\
\hline $\begin{array}{l}\text { Investimento total } \\
\text { (contos) }\end{array}$ & 419449 & 433448 & 282167 & 359940 & 252192 & 327958 & 2075154 \\
\hline Subsídios (contos) & 230697 & 238396 & 155192 & 197967 & 138705 & 180377 & 1141334 \\
\hline Capitais próprios (contos) & 188752 & 195052 & 126975 & 161973 & 113486 & 147581 & 933819 \\
\hline UHTs familiares a criar & 49 & 66 & 27 & 43 & 31 & 67 & 281 \\
\hline $\mathbf{N}^{\circ}$ de planos de melhoria & 40 & 70 & 60 & 72 & 60 & 77 & 359 \\
\hline $\begin{array}{l}\text { UHTs familiares por } \\
\text { plano de melhoria }\end{array}$ & 1,23 & 0,94 & 0,45 & 0,60 & 0,52 & 0,87 & 0,78 \\
\hline $\begin{array}{l}\text { Investimento/UHT } \\
\text { familiar (contos) }\end{array}$ & 8616 & 6594 & 10548 & 8399 & 8252 & 4915 & 7385 \\
\hline $\begin{array}{l}\text { Subsídio/UHT familiar } \\
\text { (contos) }\end{array}$ & 4739 & 3627 & 5802 & 4620 & 4538 & 2703 & 4062 \\
\hline $\begin{array}{l}\text { Capitais próprios/UHT } \\
\text { familiar a criar (contos) }\end{array}$ & 3877 & 2967 & 4747 & 3780 & 3713 & 2212 & 3323 \\
\hline
\end{tabular}

Fonte: IFADAP. Valores calculados a partir da informação contida na amostra de planos de melhoria.

Por sua vez, o concelho de Sabrosa foi aquele onde a criação de emprego familiar foi mais reduzida e o seu custo, quer para a Comunidade Europeia e Estado Português, quer para agricultores, o mais elevado. Estas constatações podem ser explicadas por um processo de 
desertificação demográfico particularmente forte e já antigo e, mais recentemente, pelos efeitos de concentração urbana ligados à sua proximidade de Vila Real.

De referir, novamente, o caso notável do concelho de Alijó, já evidenciado na secção anterior. Neste sentido, é de salientar que é neste concelho que a criação de mais UHTs familiares por plano de melhoria é contemplada.

\subsubsection{A criação do emprego não familiar assalariado}

Quanto ao trabalho não familiar remunerado/assalariado (Quadro 5), de novo se destaca o concelho de Torre de Moncorvo, cujo número de UHTs a criar é significativamente mais elevado que nos outros concelhos, atingindo um terço do total. Conjuntamente com o concelho de Vila Nova de Foz Côa, permite a criação de mais de metade do emprego que resulta do investimento subsidiado, sobretudo pelas razões sugeridas na Secção 3.3.1.

\section{Quadro 5}

EMPREGO REMUNERADO A CRIAR E O CUSTO POR UHT, POR PLANO DE MELHORIA E CONCELHO

\begin{tabular}{|c|c|c|c|c|c|c|c|}
\hline Concelhos & Alijó & $\begin{array}{c}\text { Moi- } \\
\text { menta } \\
\text { da } \\
\text { Beira }\end{array}$ & Sabrosa & $\begin{array}{l}\text { Torre } \\
\text { de Mon- } \\
\text { corvo }\end{array}$ & $\begin{array}{c}\text { Tabu- } \\
\text { aço }\end{array}$ & $\begin{array}{c}\text { Vila } \\
\text { Nova } \\
\text { de Foz } \\
\text { Côa }\end{array}$ & $\begin{array}{c}\text { Todos } \\
\text { conce- } \\
\text { lhos }\end{array}$ \\
\hline Investimento total (contos) & 419449 & 433448 & 282167 & 359940 & 252192 & 327958 & 2075154 \\
\hline Subsídios (contos) & 230697 & 238396 & 155192 & 197967 & 138705 & 180377 & 1141334 \\
\hline Capitais próprios (contos) & 188752 & 195052 & 126975 & 161973 & 113486 & 147581 & 933819 \\
\hline UHTs remuneradas a criar & 86 & 74 & 72 & 210 & 58 & 136 & 636 \\
\hline$N^{0}$ de planos de melhoria & 40 & 70 & 60 & 72 & 60 & 77 & 359 \\
\hline $\begin{array}{l}\text { UHTs remuneradas por } \\
\text { plano de melhoria }\end{array}$ & 2,15 & 1,06 & 1,20 & 2,92 & 0,97 & 1,77 & 1,77 \\
\hline $\begin{array}{l}\text { Investimento/UHT } \\
\text { remunerada (contos) }\end{array}$ & 4877 & 5857 & 3919 & 1714 & 4348 & 2411 & 3263 \\
\hline $\begin{array}{l}\text { Subsídio/UHT remunerada } \\
\text { (contos) }\end{array}$ & 2683 & 3222 & 2155 & 943 & 2391 & 1326 & 1795 \\
\hline $\begin{array}{l}\text { Capitais próprios/UHT } \\
\text { (contos) }\end{array}$ & 2195 & 2636 & 1764 & 771 & 1957 & 1085 & 1468 \\
\hline
\end{tabular}

Fonte: IFADAP. Valores calculados a partir da informação contida na amostra de planos de melhoria. 

concelhos durienses no periodo de 1986-1997

Concluímos ainda que, apesar de Moimenta da Beira ter capacidade para a criação de emprego familiar a um custo baixo, foi neste concelho onde o custo por UHT remunerado foi o mais elevado, quer para a Comunidade Europeia e o Estado Português, quer em termos dos capitais próprios a serem avançados pelos agricultores. Independentemente dos condicionantes do ambiente externo (mercado, instituições, associativismo, etc.), em Moimenta da Beira, os sectores frutícola e, em menor grau, o pecuário, são aqueles que impulsionam a economia concelhia, e não o sector vitivinícola, que é dominante nos outros concelhos estudados. Consequentemente, na sua fase actual de desenvolvimento, onde a exploração familiar ainda é o sistema de produção proeminente nestes sectores, torna-se mais difícil e mais dispendiosa a absorção de um número significativo de trabalhadores assalariados não familiares. Por sua vez, no concelho de Tabuaço, onde aliás a vinha é a produção proeminente, o emprego assalariado a criar é baixo, mas o seu custo relativamente elevado. Este facto pode ser explicado pela posição dominante das grandes quintas vitivinícolas, em termos quer do mercado de trabalho, quer da estrutura fundiária.

\subsubsection{Idade e experiência do promotor e o efeito-emprego}

No conjunto dos concelhos estudados, são os promotores relativamente jovens, ou seja, os Jovens Agricultores devidamente inscritos e, obrigatoriamente, com idades compreendidas entre os 18 a 40 anos, que potenciam a criação do maior número de UHTs familiares. Dos 282 postos de trabalho familiar a criar, 56\% são de projectos entregues por Jovens Agricultores.

De salientar ainda que dos 636 postos de trabalho remunerado a criar, $46,5 \%$ atribuem-se a planos de melhoria de promotores com este perfil (Quadro 6). Em certa medida, estes resultados não constituem uma surpresa, uma vez que, no âmbito do segundo Quadro Comunitário de Apoio (QCA), a partir de 1993, a Comissão Europeia tornou obrigatório aos Jovens Agricultores apresentassem planos de melhoria que contemplassem a criação de, pelo menos, um posto de trabalho, fosse ele familiar ou remunerado. Porém, na nossa amostra, o montante de UHTs a criar (918) ultrapassa largamente este "plafond mínimo". 


\section{Quadro 6 REPARTIÇÃO DE EMPREGO A CRIAR POR CLASSE ETÁRIA DOS PROMOTORES}

\begin{tabular}{|c|c|c|c|c|c|}
\hline & Até 40 anos & $40 a<55$ & $55 a<65$ & 65 e mais & Total \\
\hline UHTs familiares & 56,0 & 22,0 & 15,5 & 6,5 & 100 \\
\hline UHTs remuneradas & 46,5 & 21,4 & 19,7 & 12,4 & 100 \\
\hline UHTs (total) & 49,5 & 1 & 50,5 & $\perp$ & 100 \\
\hline $\mathrm{N}^{\mathrm{o}}$ de planos de melhoria & 175 & 88 & 60 & 36 & 359 \\
\hline
\end{tabular}

Fonte: IFADAP. Valores calculados a partir da informação contida na amostra de planos de melhoria.

Reconhecemos que a idade não funciona como proxy nem da experiência empresarial, nem da racionalidade e maturidade das decisões. No entanto, esta nova geração de micro-empresários rurais, embora relativamente menos experientes em termos do número de anos consagrados às actividades agrícolas, revela atitudes mais abertas às inovações "heterodoxas" e menos avessas ao risco. Muitas vezes, estas iniciativas fazem parte de uma estratégia familiar mais alargada, que abrange várias gerações, transcendendo mesmo a unidade familiar nuclear. Investigação anterior sobre o investimento subsidiado mostra que não é invulgar um plano de melhoria de um Jovem Agricultor ser concebido e proposto por iniciativa dos pais, relegando o filho ou filha a um estatuto pouco autónomo, quer em termos da gestão da iniciativa, quer da participação na tomada de decisões empresariais. Há ainda certos casos de planos de melhoria induzidos mais pela iniciativa de "intermediários de conhecimento" (projectistas, em linguagem vulgar) do que pelo próprio agricultor. Por outro lado, não há dúvida de que muitas das iniciativas tomadas com o apoio do investimento subsidiado constituem verdadeiros business start ups, ou seja, micro-empresas rurais cujo lançamento e funcionamento inicial se caracterizam por um grau de autonomia mais elevado (Gerry, Vaz Caldas e Koehnen, 1999).

O corolário do efeito-emprego dos planos de melhoria realizados por Jovens Agricultores também merece a nossa atenção, pois $44 \%$ das UHTs familiares e mais de metade das UHTs assalariadas resultaram de iniciativas de promotores agrícolas com idades superiores a 40 anos. No caso dos postos de trabalho familiares a serem criados por promotores mais idosos, esta contribuição não é de estranhar, sobretudo porque estes 

concelhos durienses no período de 1986-1997

já teriam filhos com idade de se integrarem, eventualmente, numa actividade da exploração familiar viabilizada por um investimento subsidiado. Mas, no caso das UHTs assalariadas e, maioritariamente não familiares, é tanto impressionante como pertinente o efeito-emprego atribuível às iniciativas de promotores mais idosos.

\section{CONCLUSÕES E REFLEXÕES SOBRE POLÍTICAS DE DESENVOLVIMENTO E EMPREGO NAS ZONAS RURAIS}

Da análise dos resultados obtidos podemos tirar as seguintes conclusões: grande parte do efeito-emprego gerado resulta de investimentos que visam maioritariamente a aquisição de máquinas/equipamentos e a realização de plantações (conjuntamente 82\% do total); os pequenos projectos mostram ser, de um modo geral, aqueles que mais potenciam a criação de emprego, sendo também os que apresentam menor custo por posto de trabalho a criar; é importante o empenho e a dinâmica institucional e empresarial na construção de um ambiente propício à criação de emprego local/regional; o emprego não familiar remunerado que se prevê criar é superior ao familiar não assalariado, com um custo por UHT mais baixo, sobressaindo em ambos os casos o papel dos Jovens Agricultores.

Sem questionarmos a validade das conclusões deste trabalho, naturalmente que os resultados obtidos têm de ser perspectivados à luz dos dados disponíveis e dos métodos utilizados. Existe, contudo, um conjunto de questões ligadas às políticas de desenvolvimento e emprego nas zonas rurais que merecem a nossa reflexão, nomeadamente as seguintes:

- O facto de muitas vezes se associar a realização de investimentos em máquinas/ equipamentos e em plantações/replantações à substituição de emprego, e não à sua expansão, leva-nos a concluir ser necessário investigação adicional, não só sobre os efeitosemprego quantitativos de determinados investimentos, mas também sobre os seus efeitos qualitativos. Será que estamos perante a substituição de mão-de-obra pouco qualificada por elementos potencialmente mais produtivos (porque dispõem de equipamentos mais modernos, e em maior quantidade, e estão já munidos de uma formação técnica mais elevada e adequada)? A resposta a esta questão tem implicações na definição futura de 
políticas de modernização agrícola, nomeadamente a necessidade de promover a produtividade e a competitividade das explorações, através de medidas que mais explicitamente articulem a qualidade, tanto do investimento contemplado, como a do emprego a ser criado.

- Se o objectivo de fixação de população continuar a ser uma prioridade, os resultados obtidos neste trabalho evidenciam a importância de, na definição de critérios de avaliação/elegibilidade dos projectos agrários e no desenho das ajudas a conceder, ser dado maior apoio a investimentos de pequena/média dimensão, evitando uma enfâse exagerada nas iniciativas de grande dimensão.

- As consideráveis diferenças no número de UHTs a serem criadas pelos investimentos subsidiados e as divergências, nos custos da criação do emprego inter-concelhias, levam-nos a crer que o ambiente proporcionado ao nível concelhio pelos tecidos institucional e empresarial, bem como as suas próprias dinâmicas, desempenhará um papel, muitas vezes determinante, na criação de emprego sustentável. Parece-nos, pois, essencial criar condições para que estas instituições funcionem de modo sustentado e para que trabalhem com uma ampla participação dos agentes económicos, incluindo os empresários agrícolas, cooperativas e organismos públicos mais directamente ligados ao sector.

- O comportamento das grandes empresas agrícolas e agroindustriais durienses tem influenciado tanto a economia local como o mercado de trabalho e as oportunidades de emprego. Assim, os decisores públicos devem ter em consideração o papel importante destas empresas na formulação de medidas para melhorar a quantidade e qualidade de emprego disponível nos concelhos que enfrentam ainda o perigo de desertificação demográfica, como é o caso de grande parte dos concelhos da região do Douro. Estas empresas têm recursos, interesses, formas organizacionais e estratégias tão diferentes da maioria dos PMEs agrícolas e explorações familiares aqui estudadas, que as suas capacidades para promover a fixação de população e o valor acrescentado no próprio local de produção merecem um estudo separado.

- É de salientar a importância na consolidação do emprego do próprio promotor e a eventual criação de emprego para membros da sua família, tanto para a viabilidade económica das pequenas explorações, como para a viabilidade socioeconómica local, 

concelhos durienses no período de 1986-1997

resultante do investimento subsidiado. A implementação de políticas sectoriais e regionais deve ter em conta esta realidade.

- É indispensável continuar a desenvolver políticas que criem condições atractivas para a fixação de jovens nas zonas rurais, nomeadamente no âmbito da formação profissional, apoio à criação de emprego e empresas e a promoção de condições de vida mais consentâneas com as aspirações hoje dominantes. No entanto, apesar da prioridade dada nos últimos anos à promoção desta nova geração de empresários agrícolas, os decisores têm de reconhecer que a fixação da população através da criação de emprego não passa exclusivamente pelo apoio aos Jovens Agricultores. Há evidência substancial e convincente de que os agricultores mais idosos, mais recentemente alvo de políticas de reforma antecipada, são também investidores e empregadores com potencialidades que devem ser tidas em conta.

\section{NOTAS}

* Trabalho inserido no projecto PATAMAR (Identificação, Avaliação, Priorização e Valorização das Potencialidades Agrárias de Trás-os-Montes e Alto Douro). Os autores gostariam de agradecer: à Direcção Regional de Agricultura de Trás-os-Montes (DRATM), entidade que solicitou e acompanhou a investigação e, especialmente, ao Eng ${ }^{\circ}$. Francisco Abreu Lima; ao PAMAF, entidade financiadora; e ao IFADAP, tanto ao seu Presidente, que autorizou o acesso aos planos de melhoria analisados neste trabalho, como aos técnicos da delegação de Vila Real, na pessoa da Eng $^{\mathrm{a}}$. Ana Moldão, que facilitou a nossa compreensão dos planos de melhoria, bem como dos processos de avaliação técnico-financeira, selecção e acompanhamento adoptados pelo Instituto. É importante salientar que, ao longo do processo de análise dos planos de melhoria e na preparação deste trabalho, o anonimato dos promotores foi escrupulosamente respeitado.

${ }^{1} \mathrm{O}$ peso relativo dos sectores primário e terciário, por concelho, nos Censos de 1970, 1981 e 1991 foi o seguinte: (a) Alijó: 66\%, 62\% e 47\% versus 24\%, 24\% e 38\%; (b) Moimenta da Beira: 72\%, 53\% e 40\% versus 18\%, 27\% e 40\%; (c) Sabrosa: $75 \%, 68 \%$ e $43 \%$ versus $17 \%$, 19\% e $38 \%$; (d) Tabuaço: $70 \%, 56 \%$ e $46 \%$ versus $19 \%, 24 \%$ e $33 \%$ (CCRN, 1986; INE, 1991).

${ }^{2} \mathrm{O}$ peso relativo dos sectores primário e terciário, por concelho, nos Censos de 1970, 1981 e 1991 foi o seguinte: (a) Torre de Moncorvo: 70\%, 56\% e 44\% versus 22\%, 27\% e 40\%; (b) Vila Nova de Foz Côa: 76\%, 51\%, 41\% versus 16\%, 27\% e 40\%. (CCRN, 1986; INE, 1991). 
${ }^{3}$ Com maior expressão em Vila Real com cerca de 63\% (Rebelo et al., 2001).

${ }^{4}$ A análise deste aspecto da viabilização da economia local constitui um dos objectivos do projecto em que o presente trabalho está inserido.

${ }^{5}$ Considera-se uma UHT a quantidade de trabalho que um trabalhador activo agrícola presta durante um ano, em condições normais, e que corresponde a um período de 1920 horas ( 240 dias no ano x 8 horas/dia).

6 É escassa a evidência empírica fornecida pelas diferentes fontes de autofinanciamento dos investimentos realizados na economia agrícola. Contudo, parece que uma parte significativa dos capitais próprios provém dos depósitos correntes familiares. Quando o promotor recorre ao crédito bancário, são as Caixas de Crédito Agrícola Mútuo e, dentro dos bancos comerciais, a Caixa Geral de Depósitos, as instituições que normalmente concedem os fundos solicitados. No caso de promotores mais jovens, a casa e/ou a exploração agrícola dos pais funciona amiúde como garantia do empréstimo.

${ }^{7}$ Optámos por agrupar os investimentos desta forma, uma vez que grande parte dos agricultores investiram em máquinas e equipamentos. Tendo em consideração o seu elevado preço, decidimos criar classes de investimento que incorporassem o custo típico do que consideramos uma unidade "indivisível” de capital fixo, por exemplo, um tractor ou equipamento comparável.

${ }^{8}$ Incluindo, por exemplo, itens desde tractores até câmaras de refrigeração e mesmo linhas de engarrafamento.

${ }^{9}$ Da dinâmica do tecido empresarial desencadeada e/ou consolidada por este tipo de investimentos dependerá a maior ou menor fixação de postos de trabalho, a nível regional.

${ }^{10}$ Hesitamos em qualificar este acréscimo por "novos postos de trabalho", pois não é possível determinar em que medida os trabalhadores a serem integrados nas explorações agrícolas analisadas estariam no desemprego, subemprego, ou provinham de empregos, na sua perspectiva, menos satisfatórios.

${ }^{11}$ Presentemente, os salários agrícolas rondam os $3000-4000$ escudos por dia ( $€ 15$ - €20), para trabalhadores não ou semi-qualificados, e $6000-8500$ escudos por dia $(€ 30-€ 42)$, para um número relativamente restrito de trabalhadores especializados. 
O emprego agrário e o investimento subsidiado: evidência inicial de seis concelhos durienses no periodo de 1986-1997

\section{REFERÊNCIAS BIBLIOGRÁFICAS}

CALDAS, José Vaz e REBELO, João (2001), Technical efficiency and productivity growth in the farming system of the Douro region, Portugal: a stochastic frontier approach (SFA). Comunicação apresentada no VIII Encontro Nacional da APDR, em Junho-Julho, Vila Real.

COMISSÃO DE COORDENAÇÃO DA REGIÃO NORTE (1986), A Região Norte em Números. Divisão de Estatística, Porto.

FUNDAÇÃO REI AFONSO HENRIQUES - FRAH (2000), Dossier de Candidatura do Douro a Património Mundial, Porto.

GERRY, C., António, C. P., e PORTELA, J. F. G. (2001), “A transição dos jovens da escola para o mercado de trabalho: o concelho de Santa Marta de Penaguião", comunicação apresentada ao $1^{\circ}$ Congresso de Estudos Rurais, UTAD, Vila Real, Setembro 14 e 15, 16 p.

GERRY C., CALDAS, José Vaz e KOEHNEN T. (1999), “O boom no investimento em estufas na região de Trás-os-Montes e Alto Douro, 1990-95: O perfil do 'novo' empresário agrícola”, Gestão e Desenvolvimento, $\mathrm{N}^{\circ} 8$, Universidade Católica Portuguesa (Pólo de Viseu), p. 69-94.

GOMES, Francisco Costa e ROMBO, Gonçalo (1999), Investimento, Subsídios e Criação de Emprego na Agricultura Portuguesa: Caso do Regulamento (CEE) 2328/91 em 1994-96. Colecção de Estudos do IFADAP nº1, IFADAP, Lisboa.

IFADAP (1997), Douro: projectos de investimento aprovados, 1986 a 1997, Lisboa, Instituto de Financiamento de Apoio ao Desenvolvimento da Agricultura e Pescas.

INSTITUTO NACIONAL DE ESTATÍSTICA - INE (1991), XIII Recenseamento Geral da População, Lisboa.

INSTITUTO NACIONAL DE ESTATÍSTICA - INE (2000). Recenseamento Geral Agrícola de 1999, Lisboa.

INSTITUTO NACIONAL DE ESTATÍSTICA - INE (2001), Censos 2001, Resultados Preliminares, 27 de Agosto.

REBELO, João (Coord.), MARQUES, C. P., RIBEIRO, M., TEIXEIRA, M. S., e REBELO, V. (2001), Plano Intermunicipal de Ordenamento do Território do Alto Douro Vinhateiro: Caracterização Socio-Económica. Departamento de Economia e Sociologia, Universidade de Trás os Montes e Alto Douro, Vila Real (Versão preliminar do Relatório Final). 